\title{
Karyological Variation between Two Taxa of Plantago major L., ssp. Major and ssp. Intermedia (Gilib.) Lange
}

\author{
R. El-Bakatoushi ${ }^{1}$ and A. J. Richards ${ }^{2, *}$ \\ ${ }^{1}$ Biology department, Faculty of Education, University of Alexandria, Egypt \\ ${ }^{2}$ School of Biology, University of Newcastle NE1 7RU, UK
}

Received July 25, 2005; accepted August 23, 2005

\begin{abstract}
Summary The two taxa Plantago major ssp. major and ssp. intermedia from different geographical regions were investigated karyologically. The separation of the two taxa depends mainly on seed number and size. The average karyotypic configuration for each population was used to contrast ideograms between populations from ssp. major and ssp. intermedia. The study revealed that the two taxa have distinct cytotypes which are somewhat correlated with seed number as an indication of taxonomic identity. The variation between two taxa is expressed by two main cytological groups based on the total form percentage (TF \%) which measures the symmetry of the chromosomes over the whole karyotype. The study also revealed that the evolution of the $P$. major group may be in part due to chromosomal rearrangement. The study concluded that most major karyotypes are more symmetrical than those of intermedia, which may be an indication that intermedia is the derived type.
\end{abstract}

Key words Karyotypes, Plantago, Chromosome, Evolution, Recombination, Mitosis.

The first consistent chromosome counts in Plantago were reported by McCullagh (1934). Other studies were made in connection with taxonomic studies in order to explain the relationships in particular groups of related species (Böcher et al. 1955, Rahn 1957, Cartier 1971, 1973, Zemskova 1977). Studies also covered the cytology of Plantago species from different phytogeographic regions (Gregor 1939, Runemark 1969, Briggs 1973). Badr and El-Kholy (1987) studied Plantago chromosomes in the Egyptian flora. Of the 10 studied species, five were found to have a basic number of $\mathrm{x}=6$ : $P$. arabica, $P$. lagopus, $P$. lanceolata, $P$. major and $P$. notata. The study revealed that $P$. major was characterised by short chromosomes and a symmetric karyotype compared with other species. In general, the karyotype in Plantago consists of medium-sized chromosomes, mostly with meta- and submetacentric constrictions, with no marked size difference between individuals in the total length of the chromosome complement. One or two pairs of chromosomes possessed secondary constrictions. The chromosomes of Plantago could be classified as metacentric, submetacentric, or subterminal. Pramanik and Sen Raychaudhuri (1997) studied the karyograms of some species of Plantago obtained from different parts of the world and revealed that karyograms had standard features. Despite homogeneity in total features, each species differed from the other in minor karyotypic details indicating the role of structural changes of chromosomes in evolution. The basic chromosome number $x=6$ is the most common among the species Plantago and may be considered the ancestral number in the genus (Badr et al. 1987).

\section{Material and methods}

Seeds were sown from two taxa Plantago major L. ssp. major ('major') and ssp. intermedia (Gilib.) Lange ('intermedia') all of which were of known identity except for one location (Table 1).

\footnotetext{
* Corresponding author, e-mail: richards@hightrees60.fsnet.co.uk
} 
The definition of the two taxa depends mainly on seed number and seed size (Van Dijk et. al. 1988, Morgan-Richards and Wolff 1999, El-Bakatoushi 2004). Seeds were germinated on moist filter paper in petri dishes; 4-5 $\mathrm{mm}$ long root tips were excised and pre-treated with aqueous solution of $0.002 \mathrm{M} 8$-hydroxyquinoline for $4 \mathrm{~h}$ at $4-5^{\circ} \mathrm{C}$. The roots were fixed for $24 \mathrm{~h}$ in a mixture of ethanol: glacial acetic acid $(3: 1 \mathrm{v} / \mathrm{v})$, and stored in the refrigerator. Roots were rinsed in distilled water, hydrolysed with $1 \mathrm{~N} \mathrm{HCL}$ at $60^{\circ} \mathrm{C}$ for $8-9 \mathrm{~min}$. The hydrolysed roots were stained with Feulgen's reagent. Deeply stained root tips were squashed on clean slides with a drop of $45 \%$ acetic acid. Some specimens were squashed in a drop of acetocarmine after Feulgen staining.

Cells with spread metaphase chromosomes were examined and photographed by photomicroscope, using $100 \times$ phase oil immersion lens and Kodak film. The chromosomes were measured from photomicrographs after scanning using Micromeasure version 3.3 computer program. Magnification taking place during photography and scanning was calculated and was defined for the Micromeasure program. All measurements are given by Micromeasure program V.3.3.

The mean karyotypes from each population were used to contrast ideograms between populations from major and intermedia. The nomenclature and classification of chromosomes were adopted from Singh and Singh (1976) as follows: The position of the centromere was taken as medium (M) and submedium ( $\mathrm{Sm}$ ) when the arm ratios ranges were $1.00-1.20 \mu \mathrm{m}$ and $1.21-2.00 \mu \mathrm{m}$ respectively. Chromosomes having secondary NOR constrictions were given the abbreviation "Sc". Chromosomes were classified arbitrarily into different types with respect to length as follows: Type A when it is $>4 \mu \mathrm{m}$; type B ranging between $3.10-4.00 \mu \mathrm{m}$; type $\mathrm{C}$ when it is $=2.10-3.00 \mu \mathrm{m}$ and type $\mathrm{D}=1.10-2.00 \mu \mathrm{m}$.

\section{The length of the two longest chromosome with satellites}

The relative length of the longest pair of chromosomes (as identifiable markers) compared to the total karyotype was taken to compare populations from both taxa.

The two longest chromosomes with secondary constrictions for each karyotype for an individual were measured. Analysis of Variance ANOVA was applied to compare the relative lengths of these chromosomes to the remainder of the chromosomes in all populations studied. The relative length of each chromosome was adopted from Singh and Singh (1976) as follows:

$$
\text { Relative length }=\frac{l}{\sum L} \times 100
$$

where $l$ is the long arm of the chromosome and $\Sigma L$ is the total length of the chromosome complement. The total form percent $(\mathrm{TF} \%)$ which measures the average degree of symmetry over the whole karyotype was calculated as:

$$
\text { Total form percent }(\mathrm{TF} \%)=\frac{s}{\sum L} \times 100
$$

Where $s$ is the short arm of the chromosome and $L$ is the total length.

\section{Symmetry of the chromosomes over the whole karyotype in both taxa}

The TF\% value was taken for all karyotypic individuals considered. A $t$-test was applied to compare $\mathrm{TF} \%$ values for all pairs of individuals. The lower the $t$-value, the smaller the difference between two populations. $T$-values obtained from $t$-test were placed in a Kulcinski table to match the degree of symmetry between each pair of the studied individuals (Table 2). The Kulcinski table was used before in comparisons between karyotypes of Hordeum murinum group with different chromosome numbers (Richards and Booth 1976) and also used to arrange 15 species of Delphini- 
um and Consolida according to overall karyotype similarity (El-Kelidar and Richards 1981).

\section{Results}

Karyological characters of the P. major group

Karyological data of all populations are presented in Table 1 . The somatic metaphases of individuals from all studied populations of both taxa major and intermedia revealed that $2 n=12$. The chromosome morphology in the $P$. major group varied between metacentric and submetacentric. The majority of the chromosomes were of the short submetacentric type C and D (Table 1). Metacentric chromosomes were more frequent in intermedia than in major. The total complement length was the highest $(40.49 \mu \mathrm{m})$ in major from Newcastle, England. The total chromosome length within the $P$. major group ranged from $18.96 \mu \mathrm{m}$ to $40.49 \mu \mathrm{m}$. No marked difference in the total chromosome length in the two taxa major and intermedia was discovered. The most symmetrical karyotype with a TF value of $45.23 \%$ was of major in USA. The symmetry of the karyotype in major ranged from $31.24 \%$ to $45.23 \%$, while the symmetry of chromosomes over the whole karyotype in intermedia ranged from $27.14 \%$ to $43.41 \%$.

Most chromosomes of $P$. major group were short chromosomes. Satellites or secondary constrictions were generally observed in all populations studied. Two pairs of NOR satellites were observed in all populations studied (Figs. 2,3). Satellite position varied within and between populations. However, it was noticed that in most populations, the satellite chromosomes were of comparable length, irrespective of their relative length compared with the rest of the chromosome complement. This suggests that the satellite pairs of chromosomes tend not to have been involved in major

Table 1. Locations, average seed number, total length of the chromosome complement (TL) and total form percent of the studies populations (TF\%)

\begin{tabular}{|c|c|c|c|c|c|}
\hline Locations & $\begin{array}{l}\text { Code } \\
\text { No. }\end{array}$ & $\begin{array}{c}\text { Average } \\
\text { seed number }\end{array}$ & TL & $\begin{array}{c}\text { Average } \\
\text { TF\% }\end{array}$ & Karyotypic formula \\
\hline P. major popl $(9,14)$ from Newcastle England & 16 & 7 & 26.1 & 40.33 & $7 \mathrm{SmC}+2 \mathrm{SmD}$ \\
\hline P. major pop3 (20) from Newcastle England & 18 & 7.8 & 26.13 & 40.54 & $1 \mathrm{MD}+9 \mathrm{SmC}+2 \mathrm{SmD}$ \\
\hline P. major pop4 (15) from Newcastle England & 23 & 8.6 & 40.49 & 31.33 & $1 \mathrm{MB}+1 \mathrm{SmB}+8 \mathrm{SmC}+2 \mathrm{SmD}$ \\
\hline P. major pop8 from Newcastle England & 14 & 9.4 & 29.08 & 41.3 & $10 \mathrm{SmC}+2 \mathrm{SmD}$ \\
\hline P. major pop7 (15) from Newcastle England & 24 & 7.8 & 38.12 & 38.12 & $7 \mathrm{SmC}+5 \mathrm{SmD}$ \\
\hline P. major pop7 (13) from Newcastle England & 25 & 7.8 & 36.68 & 39.54 & $3 \mathrm{MB}+1 \mathrm{SmB}+7 \mathrm{SmC}+2 \mathrm{SmC}$ \\
\hline P. major portpatrick England & 12 & 7 & 24.31 & 39.59 & $5 \mathrm{SmC}+7 \mathrm{SmD}$ \\
\hline P. major Labraye in Swizerland & 7 & 6.6 & 21.86 & 43.27 & $5 \mathrm{MD}+2 \mathrm{SmC}+5 \mathrm{SmD}$ \\
\hline P. major Belp, in Swizerland & 5 & 10 & 23.19 & 41.47 & $5 \mathrm{SmC}+7 \mathrm{SmD}$ \\
\hline P. major Venlo Norway & 20 & 8.6 & 39.23 & 31.24 & $2 \mathrm{SmB}+8 \mathrm{SmC}+2 \mathrm{SmD}$ \\
\hline P. major Villandry France & 13 & 8.4 & 22.77 & 38.74 & $4 \mathrm{SmC}+8 \mathrm{SmD}$ \\
\hline P. major Sarteano in Italy & 2 & 7.5 & 20.68 & 44.31 & $2 \mathrm{MC}+2 \mathrm{MD}+8 \mathrm{SmD}$ \\
\hline P. major from USA & 3 & 8.1 & 29.66 & 45.23 & $4 \mathrm{MC}+1 \mathrm{MD}+6 \mathrm{SmC}+1 \mathrm{SmD}$ \\
\hline P. intermedia pop1 (10) Newcastle England & 15 & 12 & 23.28 & 42.41 & $2 \mathrm{MC}+2 \mathrm{MD}+3 \mathrm{SmC}+5 \mathrm{SmD}$ \\
\hline P. intermedia pop3 (11) Newcastle England & 17 & 20 & 23.12 & 38.04 & $1 \mathrm{MD}+9 \mathrm{SmC}+2 \mathrm{SmD}$ \\
\hline P. intermedia Largoward in Scotland & 11 & 16 & 19.22 & 40.7 & $1 \mathrm{MD}+1 \mathrm{SmC}+10 \mathrm{SmD}$ \\
\hline P. intermedia (KO1) Denmark & 6 & 16 & 23.03 & 42.52 & $1 \mathrm{MC}+3 \mathrm{SmC}+8 \mathrm{SmD}$ \\
\hline P. intermedia Nybol Denmark & 1 & 17.8 & 27.68 & 41.52 & $1 \mathrm{MC}+2 \mathrm{MD}+8 \mathrm{SmC}+1 \mathrm{SmD}$ \\
\hline P. intermedia Venlo Netherlands & 21 & 16 & 40.07 & 27.14 & $2 \mathrm{MC}+6 \mathrm{SmC}+4 \mathrm{SmD}$ \\
\hline P. intermedia Noordpolderzijl Netherlands & 22 & 14.2 & 39.02 & 29.49 & $1 \mathrm{MB}+10 \mathrm{SmC}+1 \mathrm{SmD}$ \\
\hline P. intermedia Laudal Norway & 19 & 18 & 37.13 & 31.9 & $3 \mathrm{SmB}+6 \mathrm{SmC}+3 \mathrm{SmD}$ \\
\hline P. intermedia Yseel to Denver Netherland & 10 & - & 21.04 & 41.41 & $4 \mathrm{SmC}+8 \mathrm{SmD}$ \\
\hline P. intermedia Suamur France & 8 & 20 & 20.65 & 41.49 & $1 \mathrm{MD}+2 \mathrm{SmC}+9 \mathrm{SmD}$ \\
\hline P. intermedia Waldhut Germany & 9 & 16 & 18.96 & 43.41 & $2 \mathrm{MD}+1 \mathrm{SmC}+9 \mathrm{SmD}$ \\
\hline P. intermedia Benalis Athens (Greece) & 4 & 17 & 21.87 & 42.19 & $4 \mathrm{MD}+5 \mathrm{SmC}+3 \mathrm{SmD}$ \\
\hline
\end{tabular}




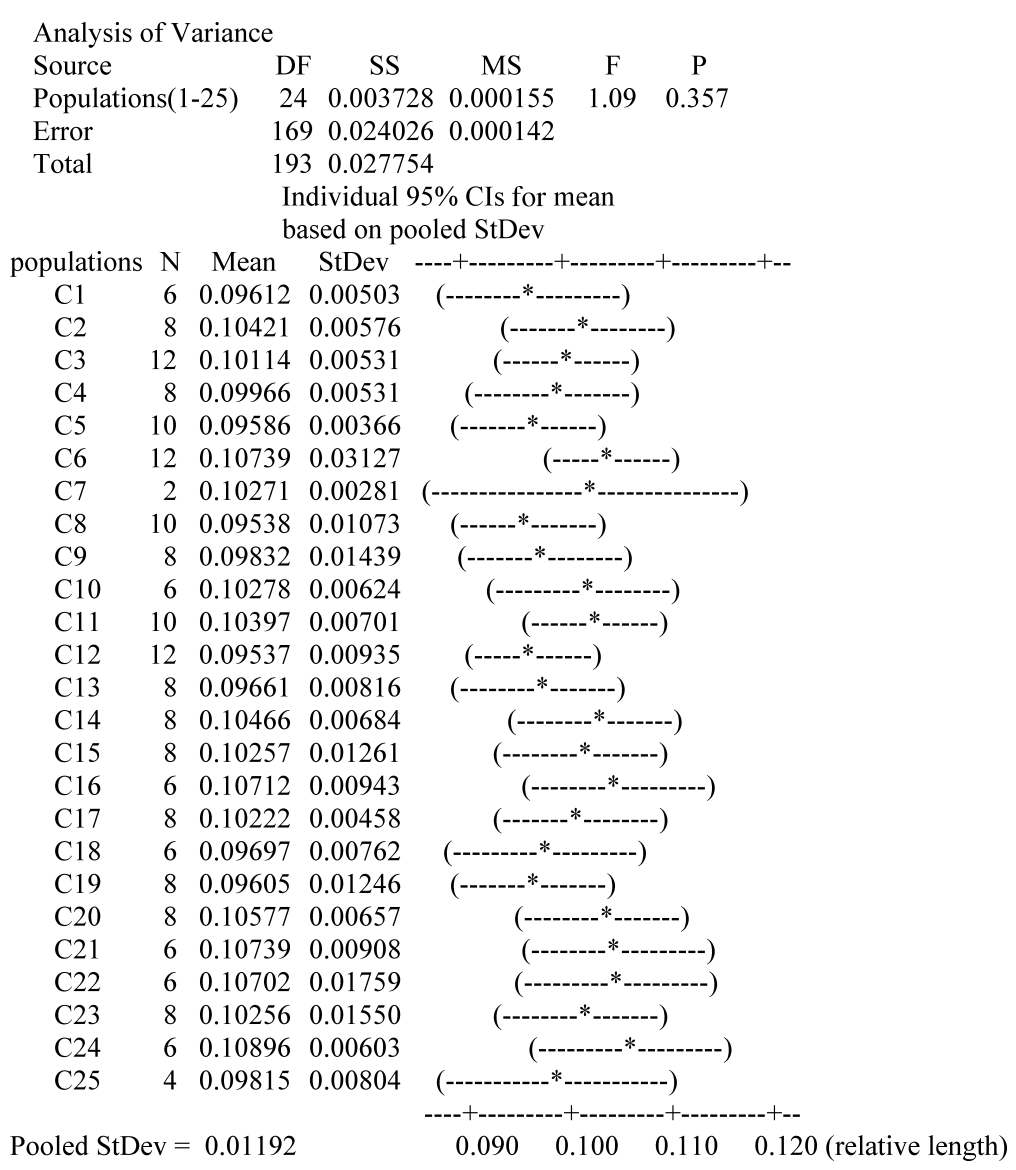

Fig. 1. Relative lengths of the two longest chromosomes with secondary constrictions.

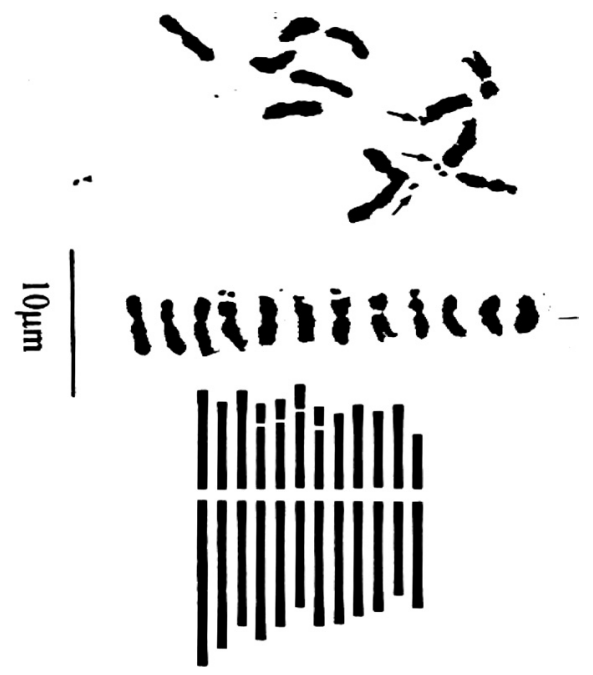

Fig. 2. Karyotype and ideograms representative of $P$. major (group 1).

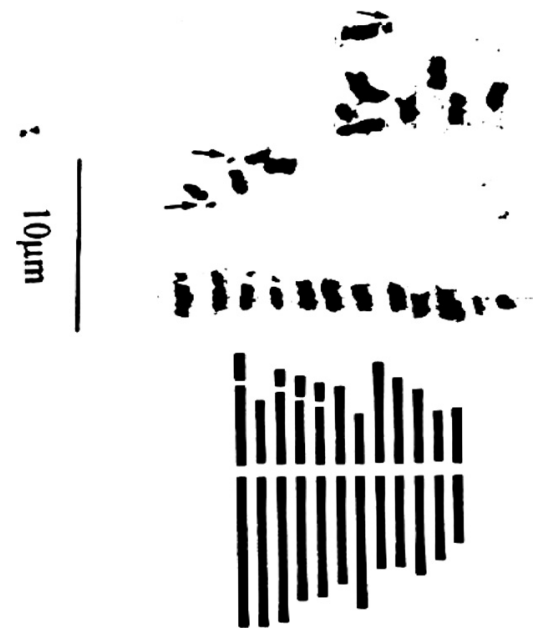

Fig. 3. Karyotype and ideograms representative of $P$. intermedia (group 2). 
recombinational events. Satellites were mostly found in long chromosomes due to the characteristic long separation distance between the satellite point and the long arm in most of the individuals studied. This may cause the differences observed in the size order of these chromosomes, although they have nearly the same relative length in all cases.

The results of the Analysis of Variance (ANOVA) showed that the relative lengths of the two longest chromosomes with secondary constrictions were not significantly different between populations studied from both taxa $(p=0.357)$. These chromosomes were nearly equivalent for both taxa and they varied to some extent between populations of the same taxon (Fig. 1). One population (7)

Table 2. Kulcinski table containing $t$-test values (values are TF\% values of studied populations) (grey squares represent $t$-values less than 1) (numbers in first column are population code numbers)

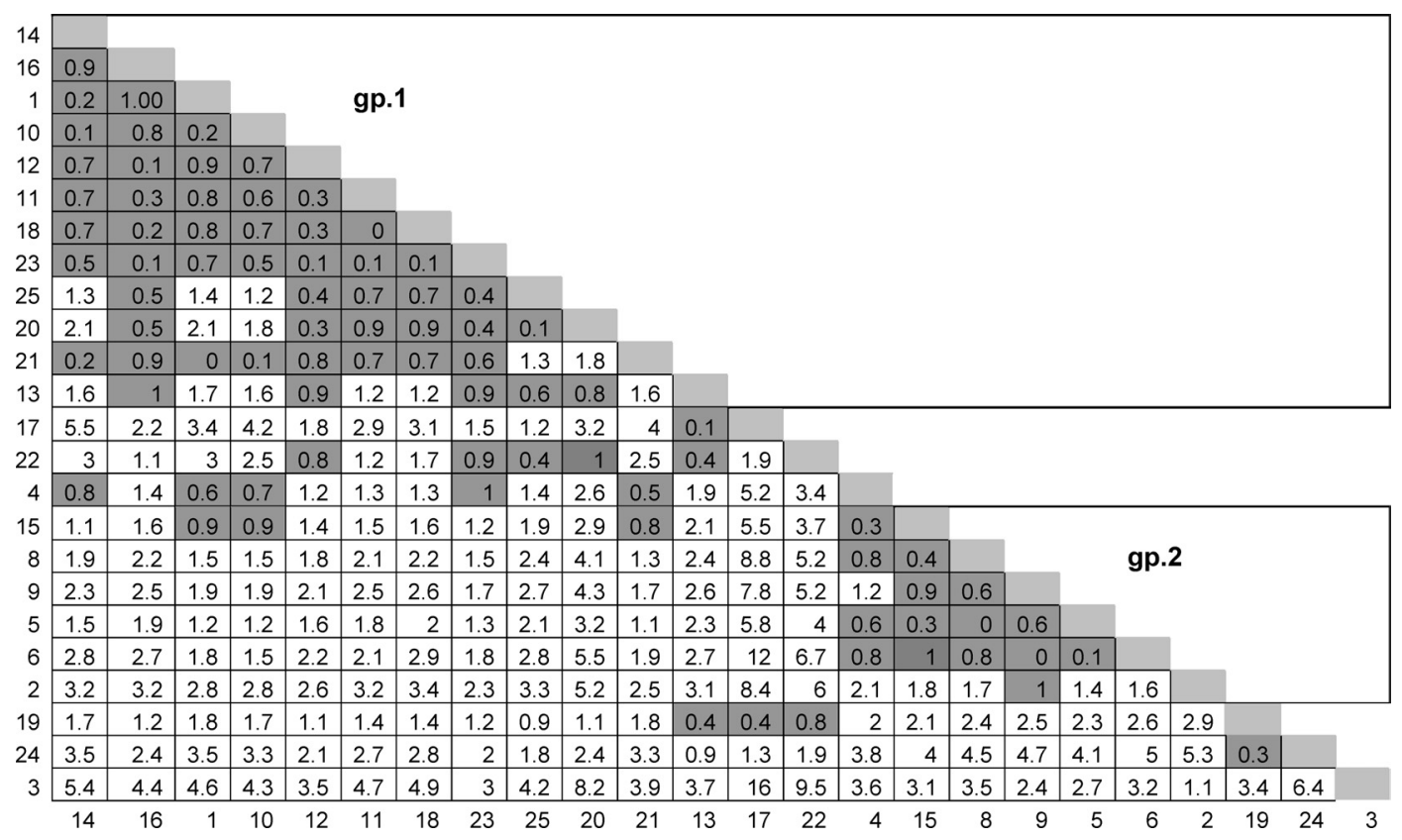

Table 3. Analysis of Variance of the seed number of the 2 main karyological groups

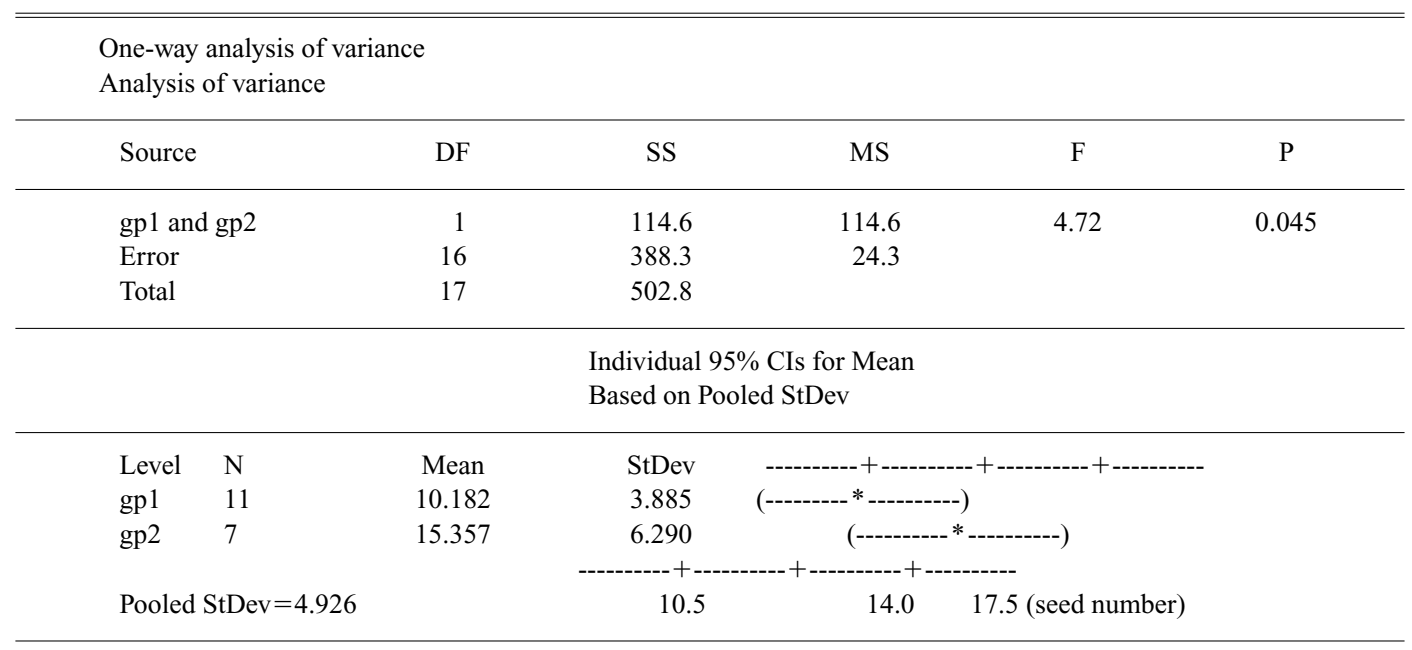

* Indicate mean value. 
had a wide range of relative lengths, probably due to the lowest number of individuals investigated (two only). These result showed congruence with data of the total chromosome length in both taxa, in which the total length of the chromosomes in major ranged from $20.68 \mu \mathrm{m}$ to $40.49 \mu \mathrm{m}$, and the total length of the chromosomes in intermedia occupied the same range (18.96-40.07 $\mu \mathrm{m})$.

Based on the $t$-value, the similarity between karyotypes of different populations were ranged from $0-8.2$. The highest degree of similarity was considered at $t$-test value less than 1 . Two main groups were separated in the Kulcinski table depending on the average degree of symmetry of chromosomes over whole karyotype. Each group contained individuals very similar to each other in the average degree of symmetry (Table 2). Most of individuals of group one were characterized by small average seed number, while the second group was characterized by a high average seed number (Table 2). Seed number is the best character to separate major into its two subspecies major and intermedia (El-Bakatoushi 2004). Group one included twelve individuals with an average seed number ranging from 7 to 9.4, except for three individuals with average seed numbers 16 and 16.4. The second group comprised individuals with high seed number with a maximum of 26, except for one with seed number of 7.5. One way Analysis of Variance was applied for the seed number of the two main karyological groups (gp 1 and gp 2, Table 3). The two taxa (based on the seed number) were significantly different in the symmetry of the chromosomes over the whole karyotype $(p=0.045)$ (Table 3). Six individuals were ignored of large differences between their replicates (individuals) (some of them were in early metaphase).

A $t$-test was also applied to compare sites and populations using the values of the relative length of the two longest chromosomes with secondary constrictions. This did not reveal any regular pattern using the Kulcinski table.

\section{Discussion}

At the level of species, the evolution and divergence of species of higher plants are often associated with large variation in nuclear DNA amounts (Rees and Jones 1972). Most of these variations are due to amplification of DNA sequences in the chromosomes (Narayan 1982). The activity of chromosomal mutations such as deletions, insertions, inversions, translocations, and duplications can be enhanced by inbreeding or hybridisation (Levin 2002).

Completely stable karyotypes in sexually reproducing species are unlikely to occur. Little significant variation on a geographic scale has been reported in Scilla vindobonensis, S. bifolia, S. mischtschenkoana (Greilhuber and Speta 1977, 1978), Adoxa (Greilhuber 1979), several Allium taxa, Brimeura fastigiata (Vosa 1976a, b, 1979), or several Hordeum taxa (Linde-Laursen et al. 1980). In a previous study on Plantago lanceolata individuals collected from Kashmir Himalayas, although individuals were highly morphologically different, no specific differences in karyotypes of the different variants were detected (Jain 1978). The results were interpreted by Jain (1978) as morphological variants stemming from simple genetic differences.

In this study, in spite of the stability in chromosome number, there is significant karyotype variations between the two taxa studied. This variation is expressed by two main cytological groups based on the total form percent (TF \%) which measures the symmetry of the chromosome over whole karyotype. Populations defined as major based on seed number which is the best character discriminating between two taxa (Van Dijk et al. 1988, Morgan-Richards and Wolff 1999, El-Bakatoushi 2004), tend to have TF \% values higher than those defined as ssp. intermedia (they are more symmetrical). This suggests that major has the more symmetrical karyotype than intermedia which may be the derived type.

While there is no significant variation between the total chromosome lengths of both taxa, the two cytotypes are significantly correlated with morphology, as documented before in P. albicans (El-Bakatoushi 1997). Stebbins (1950, 1958) and Stebbins and Dawe (1987) reported that the sym- 
metry of karyotype is decreased by pericentric inversion and unequal reciprocal translocations. Translocations seem to be the most common form of chromosomal rearrangement within plants. It was observed in a previous meiosis study of $P$. albicans that the percentages of translocations in populations were correlated with the symmetry of the karyotypes (El-Bakatoushi 1997). Whether all chromosomes are involved in translocations or not is unknown. If all chromosomes are involved in translocations, translocation heterozygotes will result. The presence of translocation heterogeneity also arises from a tendency for chromosome breakage that may be enhanced by inbreeding (Levin 2002). It was evident many years ago that chromosomal evolution via rearrangements, especially translocations, has accompanied morphological evolution in a multitude of plant genera (Darlington 1932, Lewis and John 1963).

These two subspecies of $P$. major seem to keep distinct with morphological and some genetical markers, although both taxa occur together in the same habitat in many of the studied populations. However, hybridization takes place between the two taxa and produces healthy looking individuals. Most of the character inheritance after crosses between the taxa shows matrilineal effects (El-Bakatoushi 2004). This could mean that parts of the chromosomes which influence characteristic features of both taxa can be exchanged between taxa. If these two taxa have become distinct due to the establishment of chromosome rearrangement leading to the formation of two karyotypes, nevertheless, it seems that these rearrangements do not involve the whole chromosome and have not resulted in reproductive isolation between the taxa.

Linked loci may be concerned with the fitnesss of individuals in the specific environmental conditions of the two taxa. P. major species is protogynous but this mechanism seems to be rather ineffective in preventing self-fertilization, because populations of this species are highly homozygous (Van Dijk and Van Delden 1981). Distinctness of the subspecies may result from the high selfing rate which is an important factor in the maintenance of gene complexes, consisting of such fitness-affecting genes.

The limited number of individuals used in this study for both taxa has shown karyological differences between these taxa. Further molecular karyosystematics and a meiosis study will give us more understanding about the evolution of these taxa, especially at the low level of difference that exists between them.

\section{References}

Badr, A. and El-Kohly, M. A. 1987. Chromosomal studies in the Egyptian flora II. Karyotype studies in the genus Plantago L. Cytologia 52: 725-731.

Böcher, T. W., Larsen, K. and Rahan, K. 1955. Experimental and cytological studies on plant species III. Plantago coronopus and allied species. Hereditas 41: 423-453.

Briggs, B. G. 1973. Chromosomal studies on Plantago in Australia. Contr. New South Wales Natl. Herb. 4: $399-405$.

Cartier, D. 1971. Etude biosystematique de quelques especes du genre Plantago (Tourn.) L. (sections Coronopus DC. et Oreades Decne.). I. Historiques races chromosomiques de Plantago alpina et de Plantago serpentina All. Rev. Gen. Bot. 78: 493-556.

- 1973. Etude biosystematique de quelques especes du genre Plantago (Tourn.) L. IV. La section Orcades Decne. Rev. Gen. Bot. 80: 129-149.

Darlington, C. D. 1932. Recent Advances in Cytology. Ed 2. Churchill, London.

El-Bakatoushi, R. 1997. Cytogenetical diversity of Plantago albicans L. populations growing in different habitats of North Western desert of Egypt. M. Sc. Thesis, University of Alexandra. Egypt.

- 2004. Population genetics and evolution of the Plantago major group. Ph. D. thesis, University of Newcastle, UK.

El-Kelidar, R. and Richards, A. J. 1981. Cytological indications of evolution in the genus Delphinium. Cytologia 46: 623-633.

Gregor, J. W. 1939. Experimental taxonomy. IV. Population differentiation in North American and European sea plantains allied to Plantago maritima L. New Phytol. 38: 293-322.

Greilhuber, J. 1979. C-band distribution, DNA content and base composition in Adoxa moschatellina (Adoxaceae), a plant with cold-sensitive chromosome segments. Pl. Syst. Evol. 131: 243-259. 
Greilhuber, J. and Speta, F. 1977. Giemsa karyotypes and their evolutionary significance in Scilla bifolia, S. duriensis, and S. vindobonensis (Liliaceae). Pl. Syst. Evol. 127: 171-190.

— and - 1978. Quantitative analysis of c-banded karyotypes, and systematics in the cultivated species of the Scilla siberica group (Liliaceae). Pl. Syst. Evol. 129: 63-109.

Jain, K. K. 1978. Cytology of the polymorphic Plantago lanceolata L. Caryologia 31: 179-182.

Levin, D. A. 2002. The Role of Chromosomal Change in Plant Evolution. Oxford University Press, Oxford.

Lewis, K. R. and John, B. 1963. Chromosome marker. Little, Brown \& Co., Boston, Mass.

Linde-Laursen, I. Bothmer, R. V. and Jacobsen, J. 1980. Giemsa C-banding in Asiatic taxa of Hordeum section Stenostachys with notes on chromosome morphology. Hereditas. 93: 235-254.

McCullagh D. 1934. Chromosomes and chromosome morphology in the Plantaginaceae. 1. Genetica 16: 1-44.

Morgan-Richards, M. and Wolff, K. 1999. Genetic structure and differentiation of Plantago major reveals a pair of sympatric sister species. Molecular Ecology 8: 1027-1036.

Narayan, R. K. J. 1982. Discontinuous DNA variation in the evolution of plant species. The genus Lathyrus. Evolution 36: 877-891.

Pramanik, S. and Sen Raychaudhuri, S. 1997. DNA content, chromosome composition, and isozyme patterns in Plantago L. Bot. Rev. 63: 124-139.

Rahn, K. 1957. Chromosome numbers in Plantago. Bot. Tidsskr. 53: 369-378.

Rees, H. and Jones, R. N. 1972. The origin of the wide species variation in nuclear DNA content. Intl. Rev. Cytol. 32: 53-92.

Richards, A. J. and Booth, T. A. 1976. Karyological indications of evolution in Hordeum murinum L. sl. Current Chromosome Research (ed. K. Jones \& P. A. Brandham): p. 167-174. Elsevier, North Holland.

Runemark, H. 1969. Studies in the Aegean flora X. Cytological and morphologic notes on Plantago. Bot. Notiser. 126: $9-16$.

Singh, A. and Singh, D. 1976. Karyotype studies in Trigonella. Nucleus 19: 13-16.

Stebbins, G. L. 1950. Variation and evolution in plants. Colombia University Press, New York.

- 1958. Longevity, habitat, and release of genetic variability in higher plants. Cold Spring Harbor Symp. Quant. Biol. 23: 365-378.

— and Dawe, J. C. 1987. Polyploidy and distribution in the European flora: a reappraisal. Bot. Jahrb. Syst. 108: $343-354$.

Van Dijk, H. and Van Delden, W. 1981. Genetic variability in Plantago species in relation to the ecology. I. Genetic analysis of the allozyme variation in Plantago major subspecies. Theor. Appl. Genet. 60: 285-290.

-, Wolff K. and De Vries A. 1988. Genetic variability in Plantago species in relation to their ecology. 3. Genetic structure of populations of P. major, P. lanceolata, and P. coronopus. Theoretical and Applied Genetics 75: 518-528.

Vosa, C. 1976a. Heterochromatin patterns in Allium: 1- the relationship between the species of the cepa group and its allies. Heredity 36: 383-393.

- 1976b. Heterochromatin patterns in Allium: 2-heterochromatin variation in species of the paniculatum group. Chromosoma 57: 119-133.

- 1979. Heterochromatic banding patterns in the chromosomes of Brimeura (Liliaceae). P1. Syst. Evol. 132: 141-148.

Zemskova, E. A. 1977. Karyological study of some species of Plantago 1. (Plantaginaceae). Bot. Journal. 62: 1301-1305. 